From Making Futures by Pelle Ehn, Elisabet M. Nilsson, and Richard Topgaard (eds.) - MIT Press, 2014. $\mathrm{CC}: \mathrm{BY}-\mathrm{NC}$.

http://mitpress.mit.edu/books/making-futures

\title{
6 While Waiting for the Third Industrial Revolution: Attempts at Commoning Production
}

\section{Anna Seravalli}

It is Thursday evening at STPLN, a makerspace located in an industrial building in Malmö. Davey is helping some newcomers with the milling machine. Chris and Frank are working on an old vending machine, trying to make it suitable for selling hardware boards. Someone else is mending a flat bike tire. In the textile corner, Luisa is teaching one of the hackers how to crochet. Quinn is in the kitchen, preparing food for tomorrow's catering. Some of the regulars are sitting on the sofa testing a robot they recently built. Jonathan is playing a cello he built from scrap material. In another room, a new group is experimenting with screen-printing.

The makerspace STPLN is a public workshop that provides access to machines and tools for production. Participants explore fabrication possibilities by sharing space, means, and sometimes knowledge and skills. The space is a platform for several activities, among them building robots, experimenting with new educational formats for sustainability, band rehearsals, and investigating how a café for families with small children could work. The facility is owned by the City of Malmö and is managed by an NGO. The activities are driven by citizens, small companies, groups of friends, and other NGOs.

STPLN, together with similar venues around the globe, is part of a growing network of what could be described as spaces for opening production. Through shared facilities, means of production, and knowledge, these spaces are providing citizens with the possibility to engage in production processes and to re-appropriate knowledge and practices having to do with making things. These open workshops may have different names and come in different formats (such as fab labs, hackerspaces, and makerspaces). What they have in common is the hope that they would be the venues from which the democratization of manufacturing (Mota 2011) could boost grassroots innovation (Gershenfeld 2005; Troxler 2010) that would lead to a "third industrial revolution" (Anderson 2012; Rifkin 2011; Troxler 2013). If textile companies-with steam engineswere the scene of the first industrial revolution, and automotive industries-with mass production and assembly lines-became the symbol for the second one, these spaces, with shared equipment and collaborative production processes driven by individuals outside traditional companies, may become the venue for the third one. Specifically, 


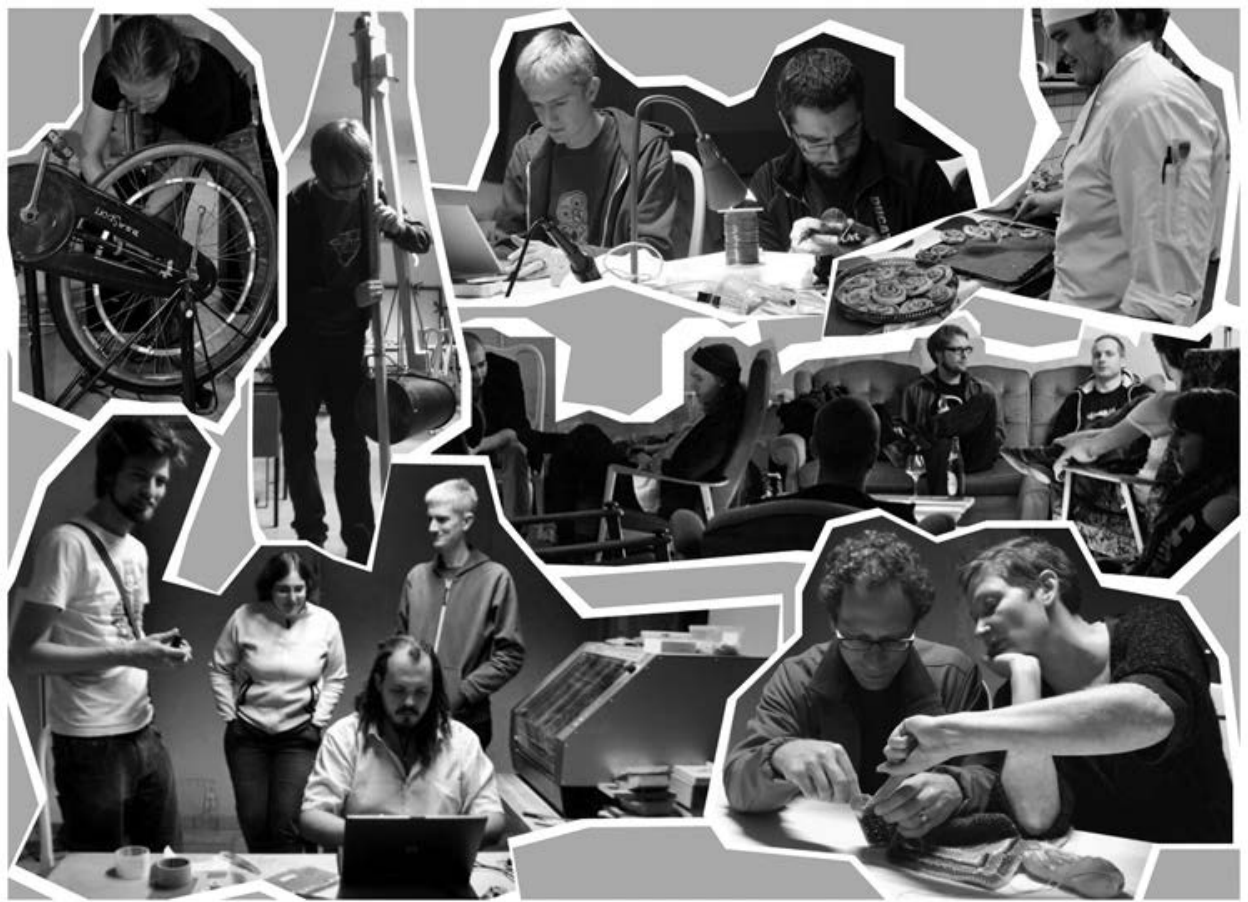

Figure 6.1

Thursday evenings at Fabriken. Anna Seravalli (CC:BY-NC).

sharing means of production and knowledge about processes and collaboration seem to entail two possible scenarios. On one side they are looked upon as the seeds for the establishment of a new mode of production in which resources and means are treated as commons, allowing for individuals to collaborate and perform production outside traditional structures (through peer-to-peer relationships). Commons-based peer-topeer production, which originated in the software field, is advocated as a more socially and environmentally sustainable way of performing production that could overcome the limits and problems of mass- and capitalist production (Carson 2010; P2P Foundation 2013). On the other hand, these practices could also be just the latest evolution of capitalist production (Bauwens 2006, 2009; Thrift 2006), with companies harvesting the commons and tapping into the creativity of open and collaborative processes.

By reflecting on the practices emerging in the everyday running of STPLN, and the way the space is organized, this chapter provides some insights into spaces for opening production by trying to enter the detail of commons-based practices, describing patterns and revealing some of the possibilities and the problems that may emerge when sharing and collaborating for making things. 


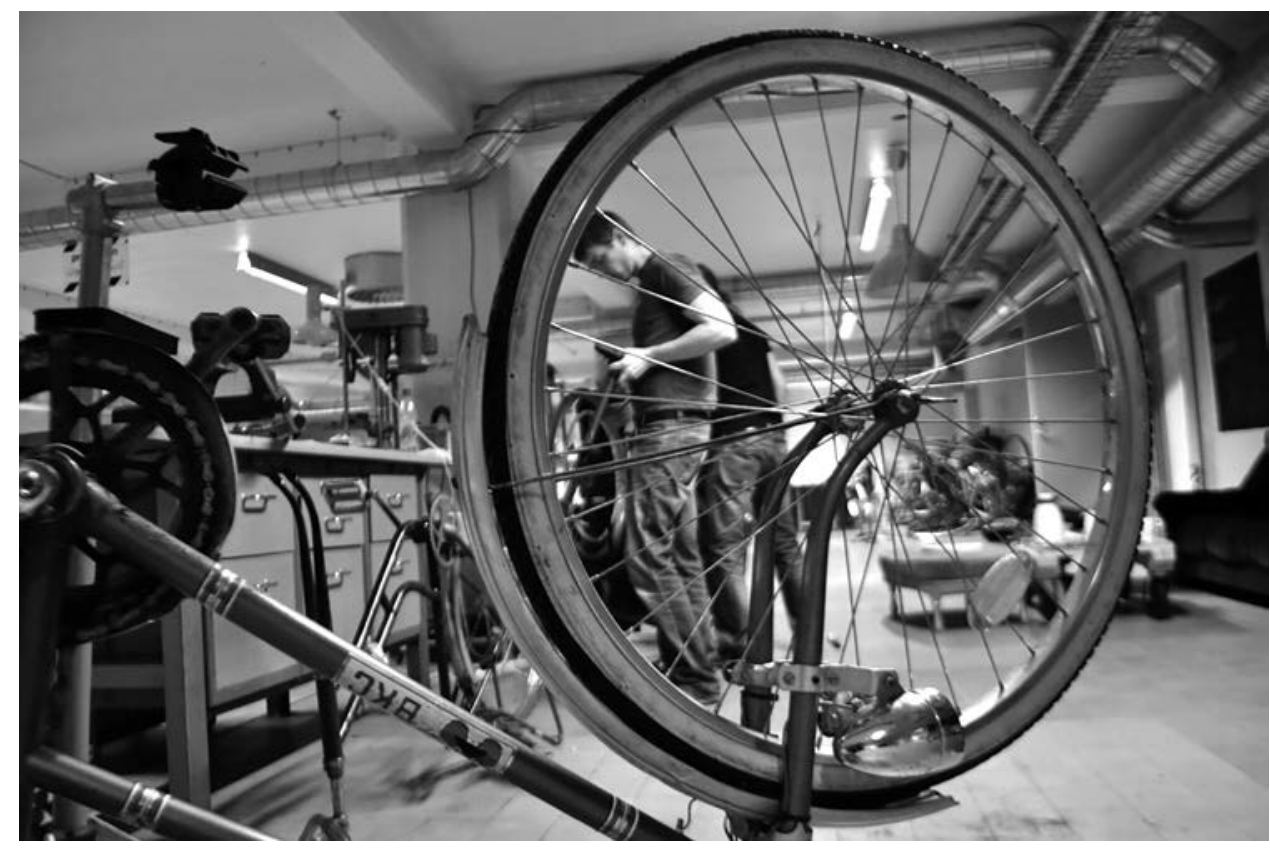

Figure 6.2

Fixing bikes at the Bicycle Kitchen. Elisabet M. Nilsson (CC:BY-NC).

\section{Welcome to STPLN!}

The STPLN building is a former workers' diner in the center of what until the 1980s was one of the largest shipbuilding sites in Europe. The building, owned by the city of Malmö, is run by STPLN, an NGO that has a history of supporting grassroots cultural initiatives. The venue can be described as a space for opening production, since it enables individuals and small organizations to engage in diverse forms of making by sharing means, knowledge, and resources. Fabriken, the actual workshop, is located in the basement of the building and is equipped with a laser cutter and a CNC mill. The workshop has also some hand tools, a saw, a sander, and equipment for working with electronics.

The basement also houses a bicycle repair workshop (the Bicycle Kitchen), a textile corner (the Textile Department), a screen-printing workshop, and a library of cast-off materials (ReCreate) that organizes activities for children and adults to foster creativity and environmental awareness. On the ground floor there is a venue for concerts, a semi-professional kitchen, and a co-working facility (HUBn).

The idea of setting up a makerspace emerged in 2006 when STPLN bought a 3D printer and started to do some workshops with kids around the city. In 2010, with the involvement of the research center Medea, financial resources to begin designing and implementing the workshop became available. The agreement was that Medea would 


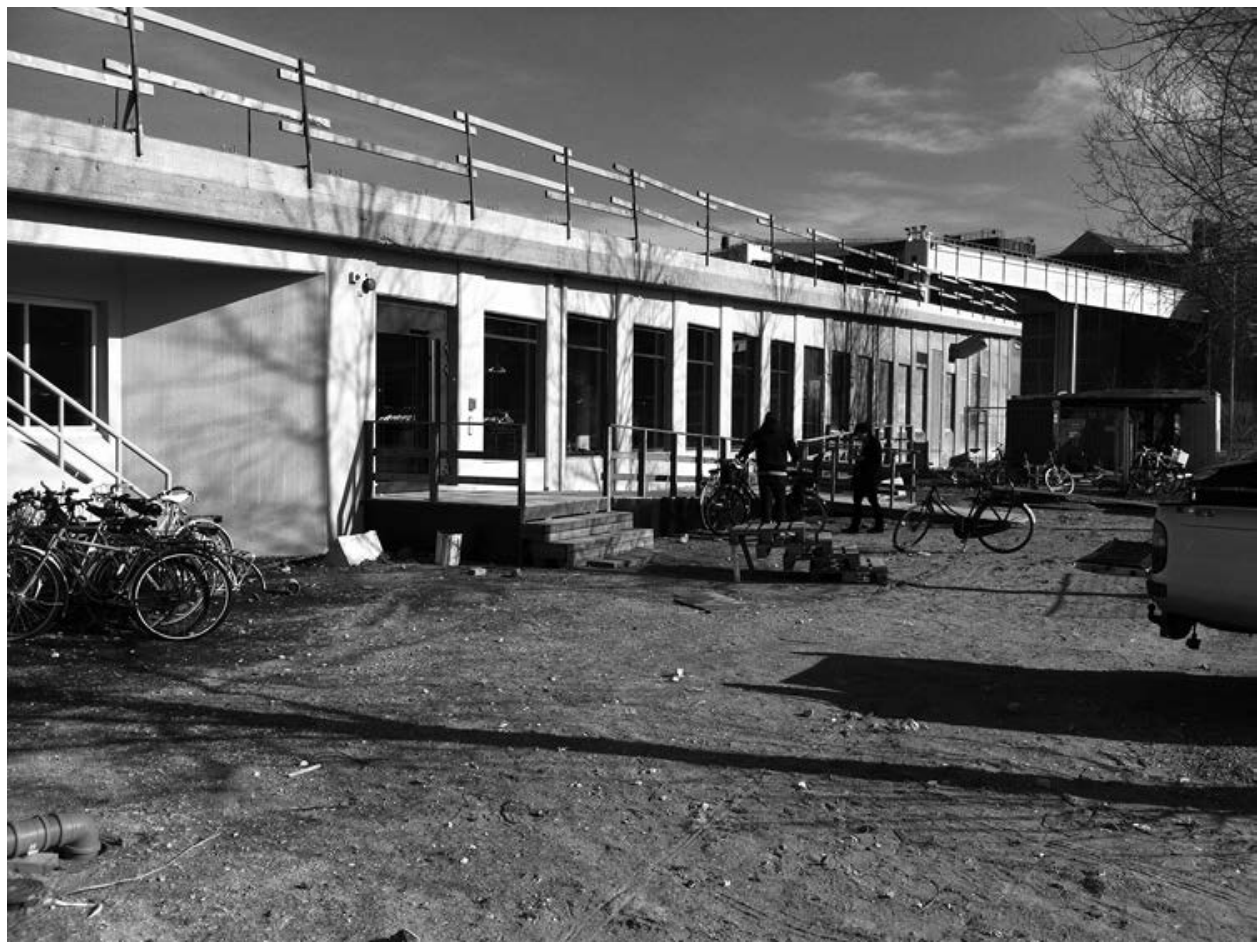

Figure 6.3

The STPLN premises. Anna Seravalli (CC:BY-NC).

provide resources to buy some equipment, and would supply a design researcher (the author) who would work with Fabriken, while the NGO would take care of the general management of the space.

I was involved in the venue for nearly three years, taking part in setting up and running the space. During that time, I took on diverse roles and carried out diverse activities, including organizing the first co-design workshops, being actively involved in setting up some initiatives, collaborating with some of the projects hosted in the space, taking part in organizing and participating in events and other initiatives, and participating in the everyday life of the space itself. (For a more detailed account of how the space was set up and of the designer's role, see Seravalli 2013.)

This chapter wishes to articulate some insights in relation to spaces for opening production and the so-called third industrial revolution. It does so by reflecting on the experiences emerging from STPLN and Fabriken, looking at how it might be possible to infrastructure for production practices based on sharing and collaboration. 


\section{Toward the future?}

The phenomenon of opening production has had a major effect on intangible, information-based forms of production. The success of FOSS (free and open source software), in terms of long-term sustainability and quality of production output, had a huge influence on the way in which the software sector operates (Benkler 2006). It massively introduced production practices based on shared resources, in which the processes are carried out by self-organized distributed communities not relying on market or managerial inputs to organize and perform production processes, that is, commonsbased peer-to-peer production (Bauwens 2009).

A commons has been defined as a "pool of resources or facilities as well as property institutions that involve some aspects of joint ownership or access" (Ostrom et al. $2002,18)$, where 'commons' can refer both to an intrinsic characteristic of the resource, in which case it is defined as a common-pool resource, or to a specific kind of management arrangement created by humans (commons as an institution) in which a specific resource is owned, managed, accessed, and used by a collective through the development of a system of shared rules and practices (Ostrom 1990). In commons-based peerto-peer production, commons are of the second kind: a way of managing resources and outputs of the production processes (Benkler 2006). Specifically, in intangible processes, resources and outputs of production processes are usually made available to anyone through the Internet, according to an open-access model. Anybody can use them, but also can contribute to them and enhance them. Thus, they can be defined as open-access commons (Benkler 2013).

This mode of production is characterized by voluntary aggregations of individuals who are entangled in production processes in which resources and outputs are shared. In terms of organization, peer-to-peer processes are characterized by equipotentiality (Bauwens 2006), which means that there is no a priori selection of who gets to participate; processes are open to anybody, and skills and capacities are verified during production. This entails that organizational structures and hierarchies are merit-based and are modified according to the kind of production activities that need to be performed (ibid.).

Benkler (2006) defines commons-based peer-to-peer production as a form of social production, since its sustainability relies on social relations rather than on market or proprietary stands, and discusses how commons-based peer-to-peer production builds on individuals' intrinsic motivations of being part of a social entity and feeling related to other human beings. Being a form of social production means that, beside generating more or less tangible outputs, commons-based peer-to-peer production is also increasing participants' social capital, which consists of the connections between individuals and the norms of reciprocity and trustworthiness that arise from them (Putnam 1995). Moreover, human capital is often generated, since, by being involved in these processes, participants have the opportunity to develop skills and competencies (Gauntlett 2011). 
If we look at the feasibility of intangible commons-based peer-to-peer production, two elements are central: the infrastructure (the Internet) and the means of production (personal computers). The Internet plays a central role in enabling commons-based intangible production processes because it lowers the costs of accessing, processing, and sharing information (the key resource in intangible production processes). Moreover, the distributed nature of the Internet eases participation, facilitating the spreading of production processes. The actual processes of production are carried out through a personal computer, which, like the Internet, allow multiple uses at the same time-for example, sending work e-mail messages, playing online games, chatting with a friend, and participating in commons-based peer-to-peer production. Thus, the cost of purchasing and maintaining a personal computer is spread across diverse uses, and this dramatically lowers the threshold of participation to commons-based production processes. The feasibility of commons-based peer-to-peer production in intangible forms is related to the fact that few resources are required to participate, since such processes can be performed through infrastructures and means of production that are acquired for and sustained through other uses. This is crucial to understanding the challenges of transferring commons-based peer-to-peer production to tangible processes. The FOSS movement has demonstrated the possibility of having commons-based production processes, but how this possibility could be transferred to other forms of production is still to be established. There are several scenarios for a commons-based provisional system (see, for example, Siefkes 2012; Helfrich 2013); some of them envisage a radical reorganization of society and of production systems. Meanwhile, commons-based peer-to-peer production may also end up being yet another transformation of production-as-usual. There have been only few successful instances in which, in establishing relationships with commercial players, opensource software projects have been able to develop ad hoc solutions to preserve the commons, avoiding allowing companies to tap into and free-ride the shared resources (Bauwens 2009; O’Mahony and Bechky 2008). Moreover, in open-source hardware, there have been a number of projects that, having thrived thanks to the contribution of a vast community, have patented and "closed" products once business possibilities have arisen. (See chapter 8.) Another issue relates to crowdsourcing initiatives in which corporate structures support users' peer-to-peer production and open up their innovation and production processes to users. Here no proper commons are generated, as ownership of and responsibility for production aren't shared. These initiatives have been celebrated as a way to support new forms of micro-entrepreneurship and self-entrepreneurship (Anderson 2010) and user-driven innovation (von Hippel 2005). However, they are also revealing another face of the so-called third industrial revolution, with companies outsourcing production tasks (but also risks) to the users (Bauwens 2009) and benefiting from free labor generated by crowdsourcing and by commons-based activities (Thrift 2006). 


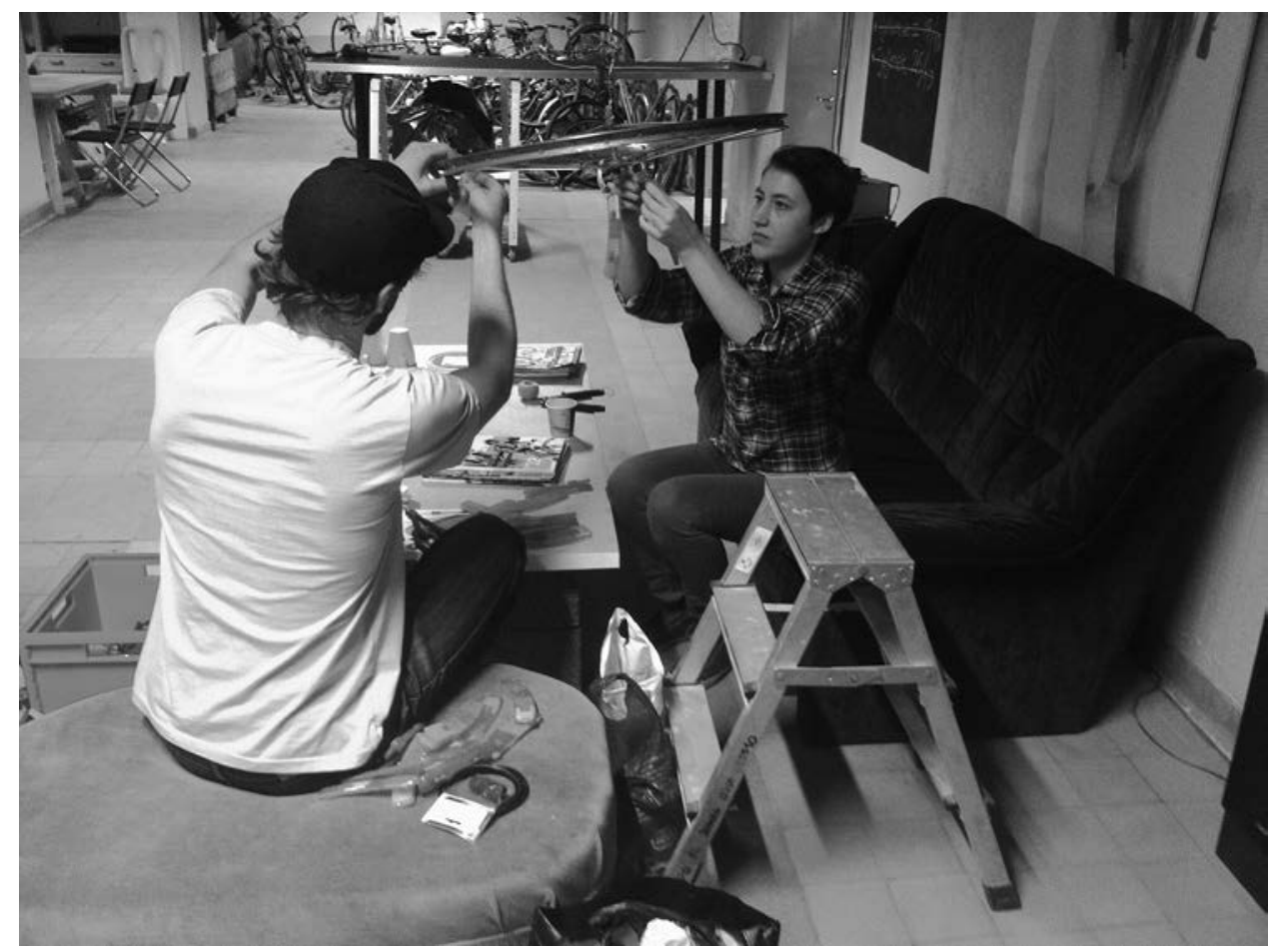

Figure 6.4

Collaborative production at Fabriken. Anna Seravalli (CC:BY-NC).

It isn't yet clear whether and in which terms the third industrial revolution is going to be a revolution, although it is already possible to see the emergence of some challenges associated with moving commons-based production from the intangible to the tangible realm and with infrastructures supporting collaboration and sharing in making things.

\section{Going tangible: Beyond openness}

The success of commons-based peer-to-peer production in information-based production processes, that is, production of intangible goods, has fostered the emergence of a number of open-source projects for the production of tangible goods and the articulation of a scenario for commons-based peer-to-peer production in the tangible realm (Siefkes 2012). As Bauwens pointed out $(2009,129)$, going tangible requires the creation of "mechanisms that combine the non-reciprocal peer production of designs for immaterial production with a separate system for physical production that relies 
on, cooperates and supports open design communities." In moving toward commonsbased tangible production, beside the need to treat information and knowledge as open-access commons, there is also the need to develop an infrastructure in which tangible means of production and resources are treated as commons.

When it comes to sharing information about tangible production processes, there are several initiatives relying on the same mechanisms used in intangible commonsbased peer-to-peer production. Proponents of open hardware and open design (van Abel et al. 2011) aim at creating and sharing files and knowledge about how artifacts work and how they can be manufactured, generating open-access commons very similar to the ones at play in FOSS. This approach seems particularly promising when it comes to production processes employing personal fabrication machines (such as 3D printers, laser-cutters, small-scale CNC mills). These machines are based on CAD-CAM systems, meaning that production processes are stirred through code and, therefore, entailing the possibility of treating atoms as bits (Anderson 2010). One of the most significant examples is the Open-Source Ecology project, which is developing opensource drawings, files, and instructions to create basic machinery for cultivation and construction.

A more challenging task is to treat tangible assets as commons, since machines and materials present the possibility that problems of rivalry and durability will emerge.

\section{Rivalry and durability}

Information and knowledge represent non-rivalrous goods, which means that they can be involved in diverse uses at the same time (Ostrom 1990). If a programmer uses a piece of code found on the Web for generating a program, she doesn't subtract the possibility that another individual will utilize the same piece of code at the same time in another production process. Knowledge and information are also durable goods, which means that they do not degrade by going through processes of production: a piece of code doesn't get worn by being used again and again, so in principle there is no cost of maintenance of the good itself. I write "in principle" because access to and provision of these goods demand an infrastructure that requires resources for its construction and maintenance. This clearly emerges in cases of intangible commons-based production in which access to code requires an Internet connection and working online platforms and repositories.

In shifting toward production processes in which tangibility has a prominent role, things get even more complex since tangible goods are rivalrous and present diverse degrees of durability (Ostrom 1990). For example, a 3D printer is a rivalrous good since it can only print one object at a time and, consequently, can be involved in only one production process at a time. As time passes, its components will wear out and eventually break down. Durability is even more critical if raw materials are considered: the plastic thread used by $3 \mathrm{D}$ printers can be used only once. In order for it to be re-used, 


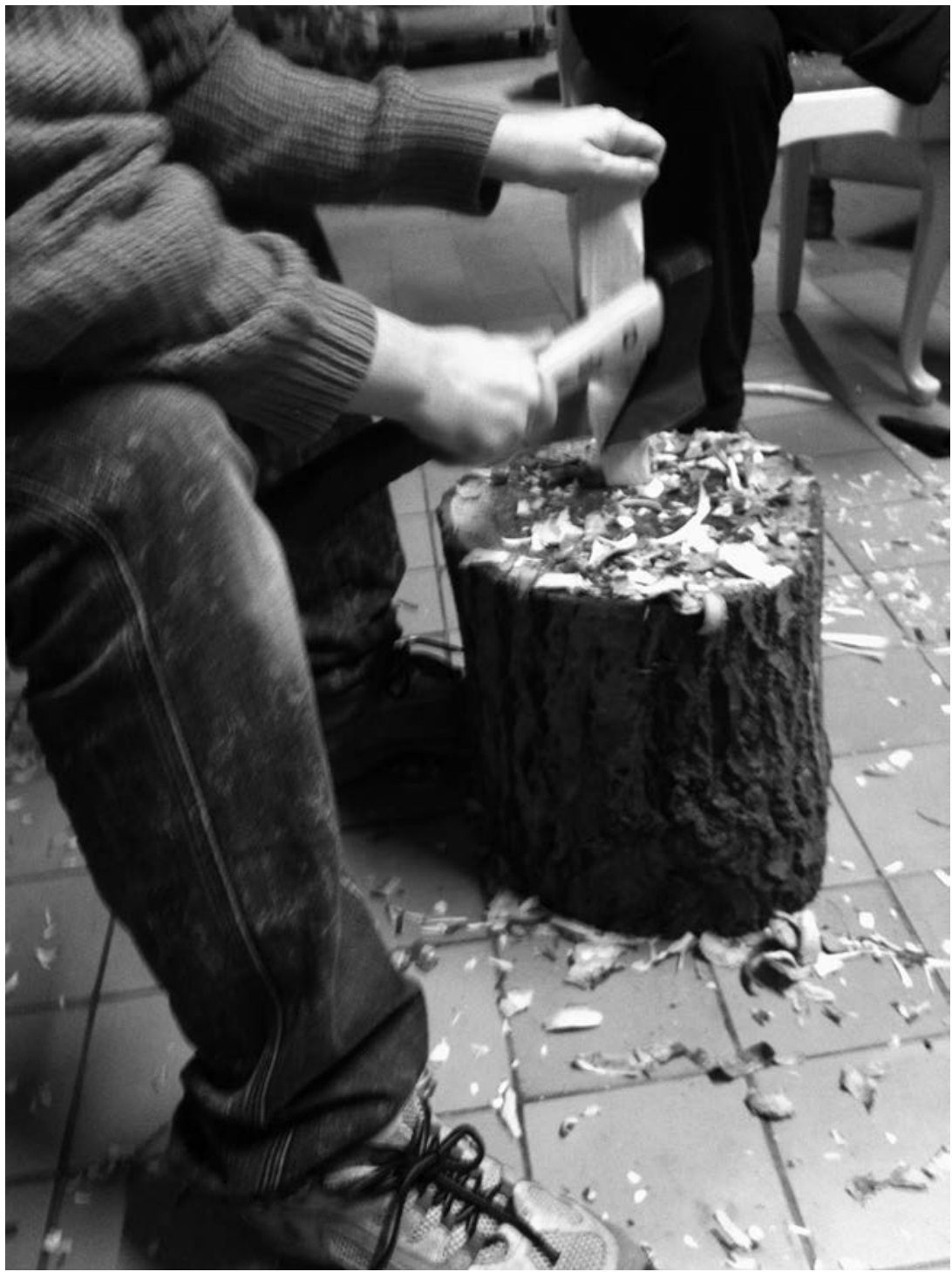

Figure 6.5

Rivalry at play in woodworking. Anna Seravalli (CC:BY-NC). 
the previous printed objects have to be melted down and the filament has to be regenerated through a process that is costly in energy, time, and means. Moreover, every time a plastic is recycled, it loses some of its physical characteristics, and after a number of cycles it is useless.

Rivalry and durability, thus, represent a challenge to the establishment of commonsbased peer-to-peer production. In working with information, it is necessary to find resources to maintain open-access commons, that is, to maintain the infrastructure and provide access to it. When it comes to tangible forms of production, beside the infrastructure challenge, there are also challenges about how to organize tangible commons assets, for example, by establishing practices for their maintenance, by finding resources to invest in these activities and, even, by introducing sanctioning mechanisms to avoid misusing of the commons and free-riding (Ostrom 1990, 1999). This implies that openness is not enough: there is a need to focus beyond the issue of access, also considering ownership, use, and maintenance of shared resources.

\section{Infrastructures: Not only distributed but also scope-based}

Another reflection that can be made about infrastructures "for going tangible" is related to the role that the Internet plays in ensuring the feasibility of intangible commonsbased peer-to-peer production. Even if the Internet plays a fundamental role in collaborative and sharing practices, it often ends up being invisible. According to Star and Ruhleder (1995), this is a key characteristic of infrastructures, which become visible only when they break down. Internet invisibility seems to be amplified by the fact that, since the Net is enabling a number of diverse activities in diverse contexts (from sending emails for work to playing online with friends), its costs are spread broadly.

A major factor ensuring the sustainability of intangible commons-based peer-to-peer production is the fact that the Internet allows for so-called economies of scope. The costs of production can be written off either by reaching scale (that is, increasing the quantity of one type of production) or by increasing the scope (that is, using the same equipment for different purposes). Economies of scope look for possibilities of involving the same means of production in diverse processes, spreading the costs of acquiring and maintaining the equipment over a range of activities (Panzar and Willig 1981).

In discussing how to establish tangible commons-based peer-to-peer production, when it comes to infrastructures, the economies of scope pattern is often forgotten. Here, the discussion (and the examples) focus on how to replicate the distributed nature of the Internet through the creation of a network of physical spaces for opening production through which users could access shared technology and collaborate beyond location constraints (Gershenfeld 2005; Carson 2010). There is little discussion of the actual self-sustainability of these hubs, how to manage and maintain them as 
commons (Troxler 2013) and, to an extent, how economies of scopes, as supporting a variety of uses and holding diverse interests together, could play a role in the viability of tangible commons-based production.

Infrastructures for commons-based peer-to-peer production supporting tangible processes therefore have to face two challenges to maintain themselves over time. The first is to deal with rivalrous and non-durable commons. The second is related to how to establish economies of scope. The next section illustrates how these challenges require us to focus not so much on the technological aspects of the infrastructure as on how it is able to support practices and uses-that is, on infrastructuring.

\section{Spaces for opening production: A matter of infrastructuring?}

The first examples of physical spaces for opening production emerged in the 1970s, with Karl Hess' shared machines shops initiative. They were neighborhood-based workshops, in which people living in the surroundings could access tools and knowledge for making things and claim back production processes:

The machine shop should have enough basic tools, both hand and power, to make the building of demonstration models or test facilities a practical and everyday activity. ... For inner-city residents the shared machine shop might be a sensible and practical doorway to the neglected world of productivity as well as being a base for community experimentation and demonstration. (Hess 2005, 96)

A similar underlying idea can be found in hackerspaces, community-operated physical places in which hackers meet and work on projects. In these spaces, tools and machines-as well as knowledge and skills-are usually shared between participants and treated as commons (Wikipedia 2011). Access to these spaces, however, usually remains restricted to so-called lead users, as emerges in the Illutron case (see chapter 7) and from an ongoing discussion inside the hacker community about the role of hackerspaces in enlarging access to the use of technology (Grenzfurthner and Schneider 2009).

A much more inclusive concept is that of the fab lab, which was developed by the Massachusetts Institute of Technology during the first mass diffusion of personal fabrication machines (Gershenfeld 2005). Fab labs build on the concept of hackerspaces as facilities for production based on shared knowledge and skills, but with a more formal structure, which make them more accessible. Fab labs have provided legitimacy and visibility to a counterculture niche phenomenon, transforming spaces in which knowledge and tools are shared for collective exploration of production processes into a network of platforms promoting the diffusion of the open and collaborative production in the tangible realm. According to the official MIT database, there were 80 fab labs in 2012 and 135 in 2013 (FabLab 2013); to these an undefined number of non-registered fab labs should be added. 


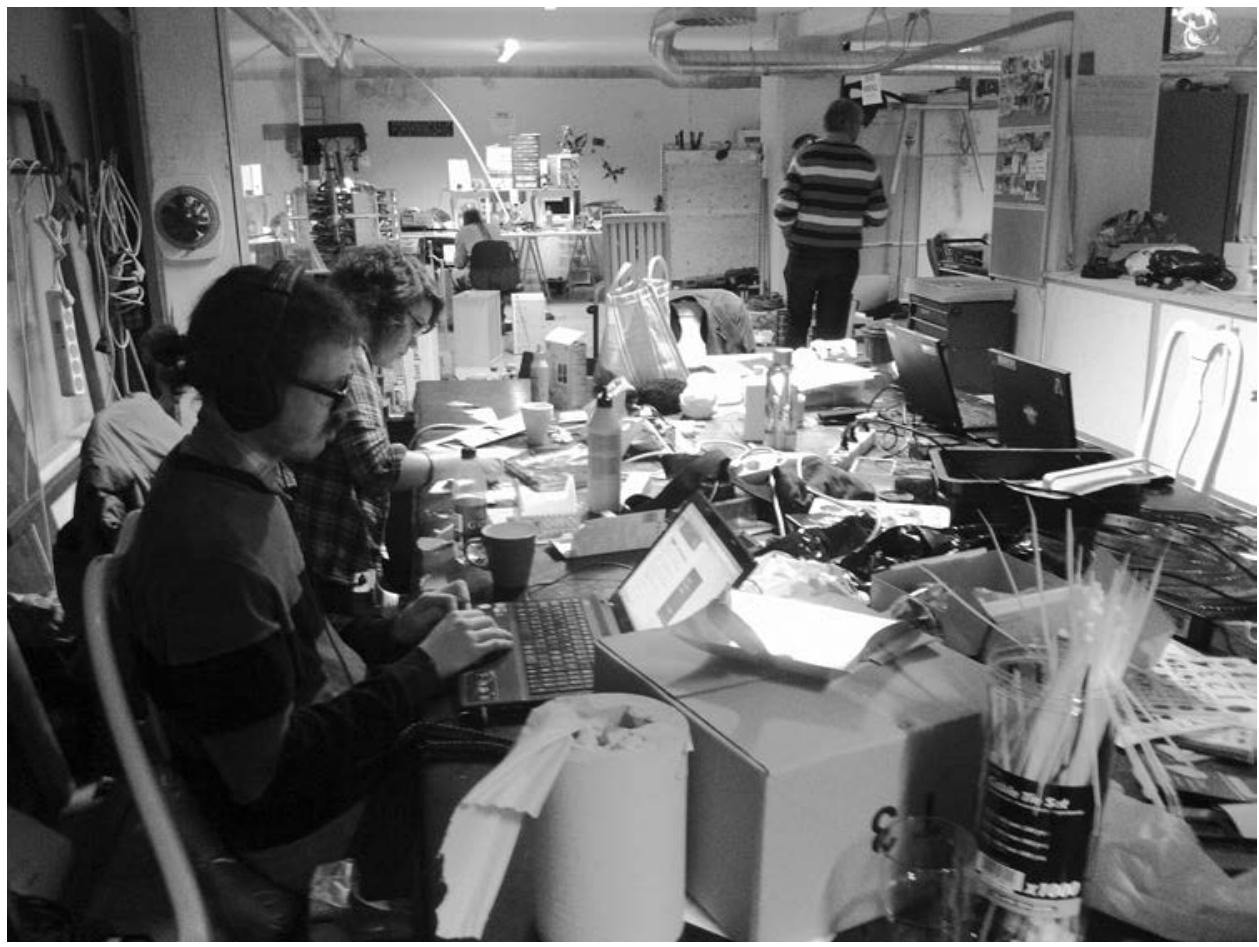

Figure 6.6

A contemporary shared machines workshop. Anna Seravalli (CC:BY-NC).

Fab labs have inspired the emergence of TechShops-commercial facilities where users, by paying a membership fee, gain access to advanced equipment for prototyping and small-scale manufacturing.

Another format is that of makerspaces. These do not have a specific definition, as Fab labs do, nor do they address specific communities, as hackerspaces do; they assume a variety of forms, usually trying to be more inclusive than hackerspaces by bringing together diverse forms of making and, consequently, diverse communities (Cavalcanti 2013). A very interesting example is the Artisan's Asylum in the United States focusing on craft production, offering access to professional equipment for small-scale production and organizing diverse kinds of courses.

In addition, a number of spaces for opening production are backed and financed by industry. Here, commons are seen as providing freedom of experimentation that eventually could lead to new ideas and products for the market (Benkler 2013).

Spaces for opening production are all characterized by the centrality of sharing (machines, knowledge, skills) and collaboration (between the participants), although 
what is shared and in what ways may differ according to their formats and aims, leading to diverse forms of commons-based production. Some such spaces are characterized by proper commons and peer-to-peer patterns, with users being directly involved in the managing and running of the hub. In others, an actor may be engaged in looking after the space and facilitating sharing and collaboration.

There are diverse expectations about these spaces. As has already been pointed out, they are looked upon as the premises that will support the development of commonsbased peer-to-peer production (van Abel et al. 2011; Carson 2010). They are also considered incubators from which a new wave of small-scale production start-ups at the intersection between crafts and the so-called Internet of Things will develop (Anderson 2012) as a result of democratizing access to production technologies and fostering collaboration between diverse expertises. Aside from a few remarkable examples (Baichtal 2011), these expectations are often far from being met. A survey on fab labs concluded that they "were primarily offering infrastructures to students," that they "were relatively passive in reaching out to potential other users," and that they "had so far created a limited innovation ecosystem, which got used rather rarely" (Troxler 2010, 9). More recently fab labs have even been declared dead (Zijlstra 2013) because of their failures in developing meaningful relationships with local actors and in promoting the sharing of knowledge and information about production on a global scale.

These critical voices seem to point to another issue that needs to be considered when thinking about how to establish an infrastructure for commons-based peer-topeer production in the tangible realm: that more than the technical aspects of the infrastructure should be considered. As Star and Ruhleder (1995) pointed out, an infrastructure is not a what; it is, rather, a when, since it becomes an infrastructure in relation to its ability of supporting a specific practice. Therefore, in trying to build an infrastructure, it is important to focus not only on the technological aspects but also on the uses, practices, and behaviors that it is able to support-that is, to think in terms of infrastructuring (Björgvinsson et al. 2010) rather than in terms of infrastructure. It is thus important to explore and understand to what extent spaces for opening production support or fail to support sharing and collaboration, what kinds of practices and behaviors emerge, who is participating, and what hindrances and challenges are present. The shift from infrastructure to infrastructuring can trigger a parallel shift from commons to commoning (Linebaugh 2009)—-that is, a shift from understanding collective ownership institutions as a what to understanding them as a when, and from something that once implemented is given and defined in time to an ongoing process of negotiation between participants, both human and non-human, in which rules and relationships are redefined according to emerging contingencies. This shift emphasizes the evolutionary and context-related nature of commons and the fact that they are not just a matter of organizing ownership but also a matter of access to and use of a resource (Hess and Ostrom 2007), and how such organization necessarily emerges in 


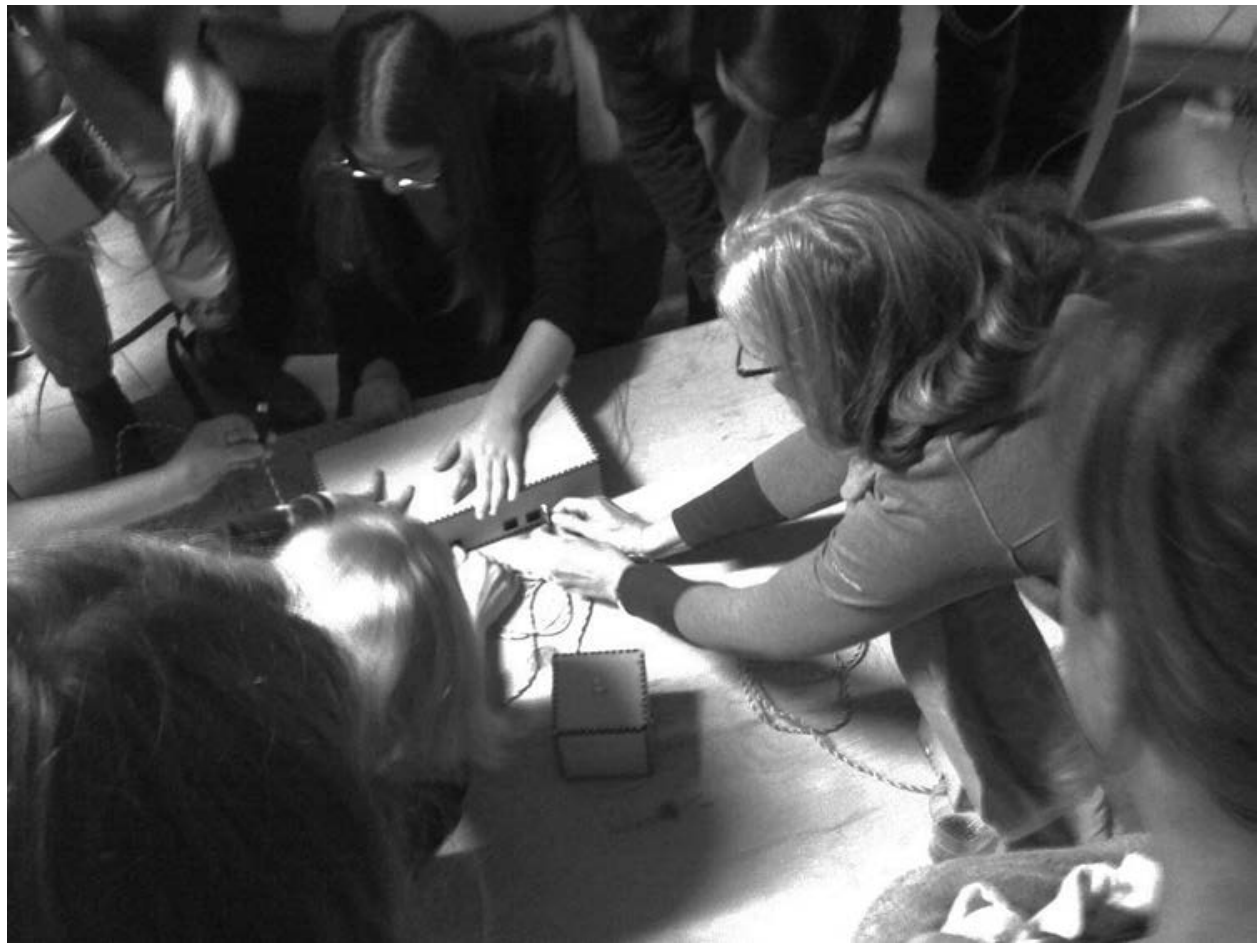

Figure 6.7

Commoning. Anna Seravalli (CC:BY-NC).

the interaction between the involved human and non-human actors. It also entails considering how rules, roles, and practices are at play in use, and how participation unfolds (Ostrom 1990, Ostrom 2011).

It is with a commoning perspective that the chapter now turns again to Fabriken and STPLN, looking at the practices, patterns, challenges, and possibilities emerging there, trying to unpack both how commons develop in time and how infrastructuring was carried out.

\section{STPLN and Fabriken: Participants, practices, and rules in use}

Fabriken is accessible when the STPLN premises are open, five days a week between 10 a.m. and 5 p.m., and this is when people can work autonomously on their projects. On Thursday evenings, Fabriken is open until late, and this is normally when diverse groups of participants are active in the space. Normally, between 10 and 30 people engage with the machines and equipment to work with electronics, and Thursday 
evenings is also when the members of the textile group, the Textile Department, meet to sew, stitch, knit, drink tea, and eat biscuits. Initially the Bicycle Kitchen was open on the very same evening, but since it was quite successful in attracting people a decision was made to move openings there to other days in order to keep the space from getting crowded. The screen-printing workshop operates mainly on Wednesday evenings; a group of volunteers, in addition to using the equipment for their own activities, organize courses and workshops for the public.

In Fabriken tools and machines are available to everybody, with the exception of the laser cutter and the CNC mill; their keys are placed in a "secret" drawer in a storage room. To be able to use them, one must come on a Thursday evening and learn from the more experienced participants. Learning and transfer of skills were, initially, not regulated through a formal system. The more experienced participants did not mind having to spend time to teach the few newcomers how the machines worked. As time went by, the number of new people coming to the space increased, and a need emerged to organize proper courses about the machines, as it was important to establish what people should be taught in order to don't ruin the equipment and to keep track of who attended the courses. The most experienced participants formally took on the tasks of education and machine maintenance. In exchange they were given a special status: beside social recognition, they were also involved in deciding what machines should be bought. However, later on, also this solution presented some problems, leading to the decision of hiring someone to take care of the space.

Diverse activities are taking place in Fabriken: repairing bikes, sewing clothes, experimenting with electronics, laser-cutting pieces for architecture models, and others. These activities are carried out by individuals or by small groups. Some are aimed at creating finished products, some at experimenting and playing around with tools, machines, and materials. Beside the private individuals who come to the space in their spare time, Fabriken has also been hosting two fashion-design ateliers and a catering company. The ateliers have been based in the Textile Department; one of them focuses on textile design in a broad sense and the other on "up-cycling" old garments. The catering company used for some time the kitchen for food workshops. These three initiatives are driven by people who have regular jobs and who, in their spare time, are trying to build professions out of their passions.

Fabriken attracts also long-term projects. One of them is ReCreate, which uses castoff materials from industrial production to build new things and to stimulate creativity and environmental awareness in children and adults. The driving force behind ReCreate is a former teacher who wanted to experiment with new ways to teach sustainability. She came to Fabriken looking for space and support for developing her idea. She began by collecting materials, prototyping formats, and holding workshops for adults and children. Moreover, she established a network in the space by getting to know the other projects and the people who gathered in the space on Thursday 
evenings. Some events in collaboration with the Bicycle Kitchen were organized, and also some workshops with Fabriken regular participants to explore new ways of using her materials. After some months, the former teacher got three years' worth of financing for developing her project.

Among the other participants in Fabriken are local hackers, programmers, and electronic musicians. The space is also frequently used by representatives of Malmö's cultural and art scene. A few students from the program in Interaction Design at Malmö University also hang around in the space. It is difficult to categorize the rest of the participants. All of them are interested in various forms of making and self-production. Most of them are well educated and have fairly well-paying jobs; however, there are also some unemployed people and some knowledge workers struggling to make a living. A few people on long-term sick leave come to the space almost every day, mainly for tinkering around and chatting, and three retirees (two engineers and a teacher) are regular visitors.

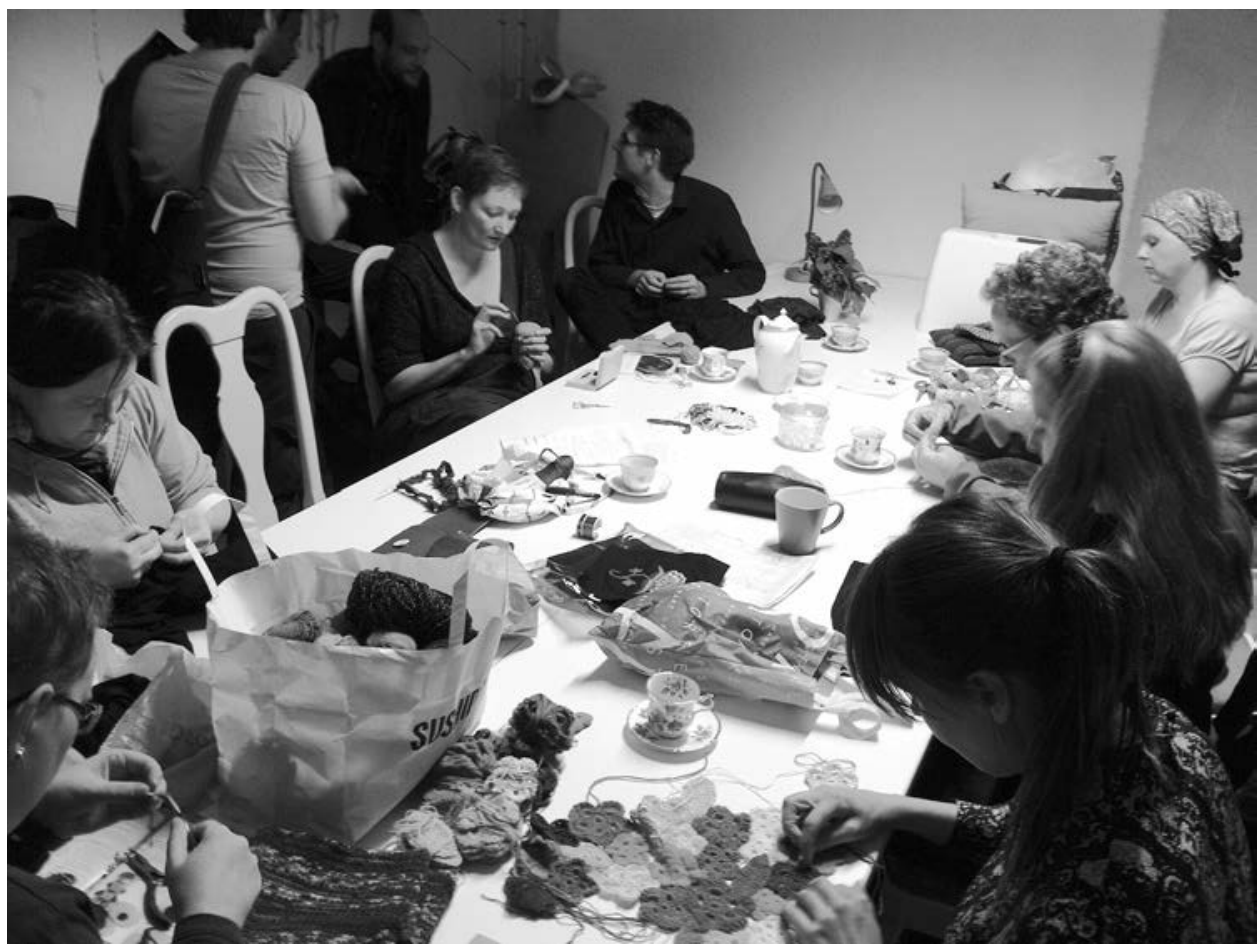

Figure 6.8

The Textile Department. Anna Seravalli (CC:BY-NC). 
The ground floor of STPLN's premises is regularly used by small companies and freelancers working in Malmö's cultural and creative scene. The space also hosts short-term projects such as a café for families with small children, a tailor service for fixing clothes, and exhibitions of emerging local artists. These initiatives are driven by people who are looking for space and resources for testing activities and ideas and check if and how they might work before making large investments.

\section{Production at Fabriken: Commons-based crafts and do-it-yourself activities}

The production processes and the activities carried out at Fabriken can be defined as commons-based in the sense that they are carried out through sharing both facilities and the means of production. Generally, initiatives at Fabriken resemble craftsmanship (Sennet 2008) since activities are often about doing something concretely by developing a direct involvement with materials through working, often becoming an opportunity to learn and to acquire new skills. At the same time, activities are often characterized by mutual learning and collaboration, generating social connections and resembling the idea of "making is connecting" (Gauntlett 2011).

Fabriken activities are generating outputs of three kinds of value: (1) goods or services with use value, (2) human capital (that is, skills and competence), and (3) social capital (social connections and trust). Here use value is understood as the concrete way in which a thing meets human need, or its being functional in satisfying a specific need (Harvey 2010). In Fabriken, use value can address a private need, or it can be exchanged with others for money or for other values such as social recognition or friendship. Moreover, having access to machines and meeting skilled people contribute to the development of human capital: personal knowledge, competence, and attributes of each participant. Sharing of spaces, machines, and knowledge supports a do-it-together approach (Gauntlett 2011) by which new connections between participants are established, generating social capital that entails connections among individuals and the norms of reciprocity and trustworthiness that arise from them (Putnam 1995).

When it comes to the activities going on in the space it is possible to distinguish between do-it-yourself practices ((Shove et al. 2007; von Busch 2008) and craft practices (Greenhalgh 2002).

The "DIY movement" began in the middle of the twentieth century, promoted by manufacturers of hand tools who saw in amateurs a potential market (Shove et al. 2007). In the 1970s, DIY practices were embraced as a form of resistance against the industrial production system (Leadbeater and Miller 2004), starting from the assumption that everyone could build and repair things (Gauntlett 2011), as opposed to buying new things, and that such activities are rewarding not only in terms of saving and/ or producing use value but also in terms of personal satisfaction and self-esteem (Shove 
et al. 2007). The idea of DIY as a critical practice was developed within punk subcultures, in which it was considered a way to reclaim music and information production through home-recorded music tapes and zines (home-made magazines) (Gauntlett 2011). Recently, DIY has also become a central practice in the sustainability discourse, since repairing and recycling are viewed as alternatives to mass consumption (ibid.). DIY as an approach to hack mass production and consumption (von Busch 2008) is also emerging in Fabriken; however, it is also possible to see the space as embedded in and heavily dependent on the current economic system, since most of the production is done as a leisure-time activity.

At the same time, some of the activities seem to have the potential to represent an alternative way of producing and acquiring things, and in that they more resemble crafts. Crafts aren't defined specifically, since they represent an assortment of genres that makes sense together for artistic, economic, and institutional reasons. They have no intrinsic cohesion, no a priori relationship that makes them a permanent peculiar or special gathering (Greenhalgh 2002). Crafts, though, present several distinct threads. This is evident in Fabriken, in which craft practices do not necessarily fall in the category of decorative arts, but they more generally include all the activities requiring "applied" forms of creativity in a broad sense, from embroidery to soldering circuits.

Nonetheless, crafts present some common traits, especially when it comes to quality, morality, and technology (Greenhalgh 2002). Whereas DIY focuses on the actual making as an appropriation of production processes and generation of human capital, the focus in crafts is more on making as a way to generate use value; therefore, crafts entail a distinctive notion of quality that brings together functionality, aesthetics, and skills.

Since the eighteenth century, with the rise of the Arts and Crafts movement based on the ideas of John Ruskin and William Morris, crafts have also been considered a more human way of organizing production processes in opposition to the alienation of industrial processes (Harvey 2010), bringing in the aspect of morality. This aspect is shared with DIY practices and the idea of production as a tool for self-expression (Gauntlett 2011). The technology aspect is also quite central. On several occasions crafts have been looked upon in opposition to technology as an expression of industrial society (Ruskin 1985). However, in Fabriken, crafts activities do actually rely on technologies as tools for improving quality, efficiency, and accessibility to practice.

DIY and crafts are not new inventions; these models of production have been around for a long time, and crafts represented a mainstream mode of production until the first two industrial revolutions. What is different in Fabriken, and at other spaces for opening production, is how DIY and crafts practices are performed through shared means of production and collaboration, which, sometimes, but not necessary, can lead to the generation of commons. 


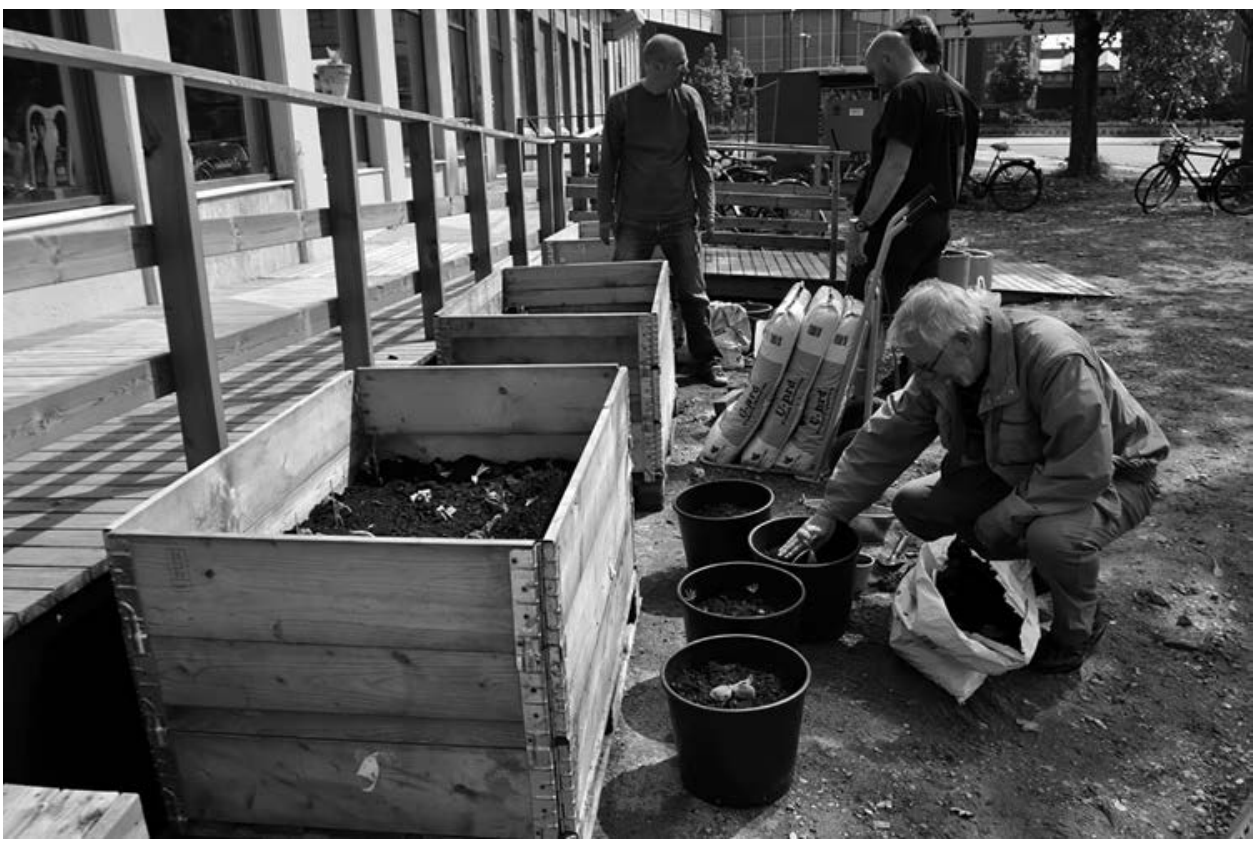

Figure 6.9

Setting up STPLN's common garden. Elisabet M. Nilsson (CC:BY-NC).

\section{Trying to overcome scarcity of materials}

A major difference between intangible commons-based peer-to-peer production and the activities at Fabriken is that in the latter materials and outputs are rarely treated as commons, largely because problems with durability and rivalry make it more difficult to share materials - once used, they aren't available for others, and, unlike information, they are difficult to produce. How to get hold of materials for production is a major challenge in spaces for opening production, since the possibility of gaining access to machines, equipment, and even knowledge doesn't generate anything if materials aren't available. Finding ways to gain access to materials has always been a main concern in Fabriken, and has led to the development of a number of strategies having to do with waste. Beside basic approaches such as disassembling electronic products in order to get parts and collecting old clothes that can then be remade or reused, more complex strategies have also been developed. The Bicycle Kitchen, for example, had an agreement with the company that handles waste in Malmö to get bikes that people no longer wanted. The company put a container dedicated to bicycles in one of its facilities in which citizens bring their garbage. Users bringing bicycles to that facility could 
then decide whether to throw them away or to donate them to the Bicycle Kitchen. Initially the same strategy was to be used to get other things for Fabriken, but that turned out to be too complicated. The practices in Fabriken were so diverse that many containers would have been needed. Moreover, some extra work would have been necessary to sort materials, since, for example, certain activities performed in the space do not require just wood in general; they require plywood, or boards, or other specific kinds of wood.

And even if we could get hold of the materials, we would not know where to store them. Recently the Bicycle Kitchen decided to stop its collaboration with the wastemanagement company because it was getting more bikes than it had space for.

An interesting opportunity seemed to arise when ReCreate entered the space, since, besides getting interesting materials, ReCreate was also sorting them out. A series of collaborative experiments ensued-for example, between ReCreate and the Textile Department in order to explore possible uses of a high-quality waterproof textile that ReCreate got from a sailmaking company. However, this was an exception rather than the rule. Most of the materials ReCreate gets are semi-finished products, already shaped and therefore not easy to reuse. Moreover, it is sometimes difficult to know the exact constituents of the things ReCreate collects, so it isn't easy to decide whether, for example, the laser cutter should be used on them.

Working with scrap and waste is a common practice in Fabriken to overcome material scarcity, although this approach is unable to fulfill the needs of most of the activities. Material scarcity makes it difficult to apply commons-based peer-to-peer production to tangible forms of production. Thus, there is a need to develop new strategies and tactics to acquire resources for tangible forms of social production.

\section{Fabriken and STPLN as attempts at commoning}

Despite the materials challenges, Fabriken has succeeded in attracting and supporting a range of production practices by lowering the barriers for performing DIY and crafts activities through shared means of production and collaboration. The machines and the space attract participants and activities, but treating them as commons has not always been easy. Commoning, it became apparent, is not just a matter of establishing shared ownership; it is also a matter of managing collective access to, use of, and maintenance of resources (Ostrom 1990). This implies that commoning is an ongoing activity that needs to continuously evolve and adapt to changes in the context (ibid.).

Since the opening of the space, the idea was to involve participants in its management and reward the most active participants with special status-for instance, keys to the space, social recognition, or the opportunity to be involved in deciding what equipment to purchase. This led to a model of managing the premises: the NGO takes care of the general functioning of the space, and the participants focus on specific tasks 


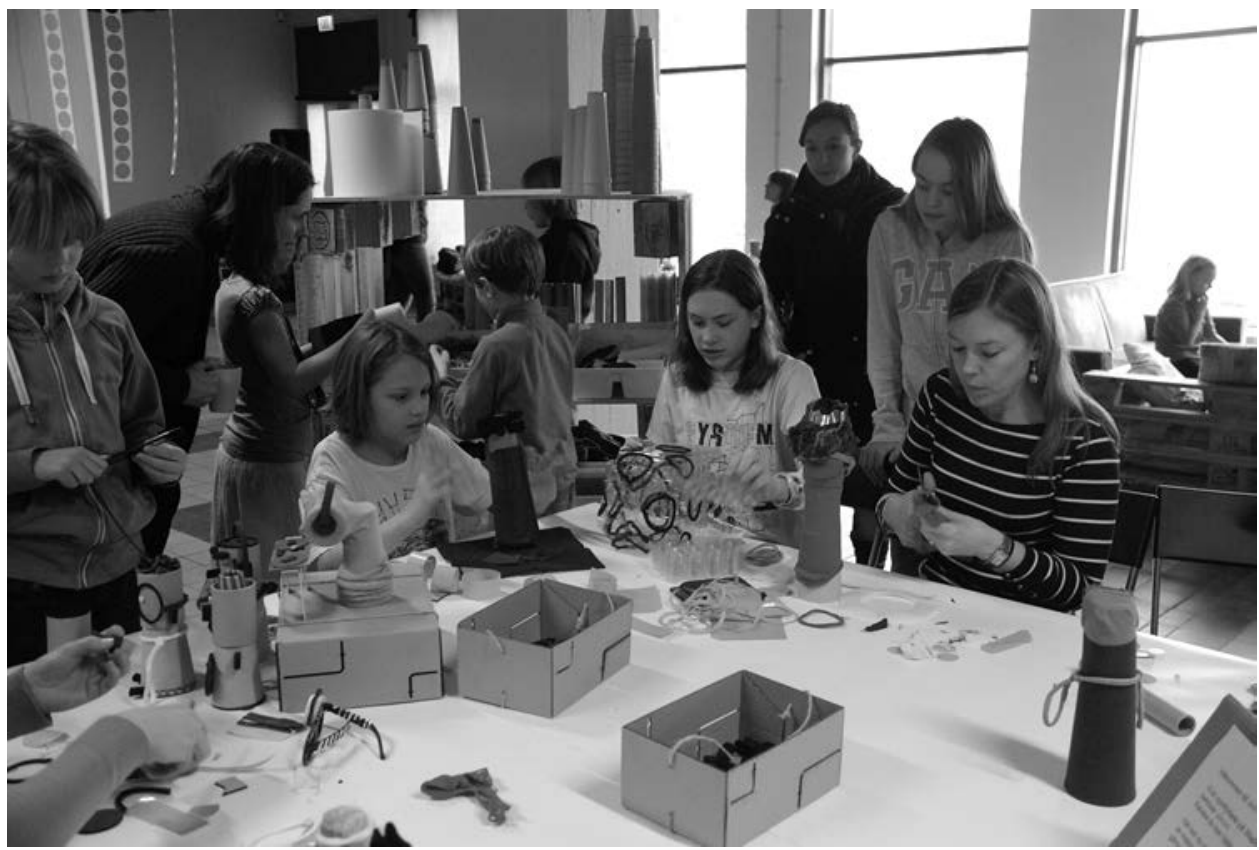

Figure 6.10

ReCreate's workshop. Anna Seravalli (CC:BY-NC).

directly connected to their own interests. The hacker community is managing and taking care of the machines in Fabriken, a small group of designers is running the textileprinting workshop, and an old lady is in charge of the textile corner. An important role is also played by the founders of ReCreate and the Bicycle Kitchen, who besides running their own projects are often involved in the general management of the space.

The functioning of the space relies on both economic standing and social standing. The NGO people and those running ReCreate and the Bicycle Kitchen are salaried. The fabrication machines, the textile atelier, and the screen-printing workshop, however, are managed by volunteers who are rewarded mainly with social standing. They usually don't get involved in general organizational issues; instead they manage access to and functioning of specific features. These highly engaged participants seem to be more interested in specific and even quite complex activities (such as fixing the laser cutter) than in the general management of the space (which is, as said, mainly a task for the NGO people and the ones driving the in-house projects). However, not all the participants are actively engaged in the space. The layers and possibilities of participation range from simply having access to and using the shared resources to taking part in their maintenance. 


\section{The NGO as a partner in commoning}

The NGO plays an important role in the complex interweaving of diverse modes of participation, overseeing the management of the premises, coordinating sharing and access, and providing financial resources for the purchase of machine parts and tools. Participants mainly contribute with time, skills, and some material resources (such as equipment and materials). The NGO can be seen as a kind of partner in the participants' production activities. Cosma Orsi (2009) used the notion of partner to describe the possible role of the state in a commons-based regime as a structure supporting and enabling citizens' initiatives. In STPLN, the NGO doesn't run or lead specific activities; rather, it provides support for the diverse projects and ensures the preservation of the commons by intervening in disputes having to do with the sharing of equipment, the space, and access to the premises.

Because the NGO is financed by the municipality of Malmö on the basis of how many activities and people it is able to mobilize, participants can exert power through their sheer presence (or, rather, absence). There is a mutual dependency between the participants and the NGO. The participants depend on the NGO for access to the space and for its basic management. The NGO is aware that without participants the premises are endangered. The NGO's role is particularly important because in Fabriken and STPLN a lot of the projects are short in duration and people easily move in and out of the space. While the NGO ensures the continuity of the commons, the participants in the space may change. The role of the NGO is ambivalent: it certainly enables commoning by facilitating sharing and collaborating between participants; on the other hand, it could also be said that the organization running STPLN hinders commoning by retaining a central role in the management of the space.

\section{Challenges with transient commoning: Legitimate participants and non-participants} Commoning at Fabriken seems to run quite well, though there are occasional tensions related to how the NGO is distributing financial resources. Specifically, the non-durability of the resources in the space implies the need for constantly investing money to maintain and fix the machines. As said, the NGO has some financial resources that, however, are never enough to cover all the material needs of the initiatives in the space, thus, discontent between participants may emerge about how these resources are allocated.

Other challenges emerged as the number of participants grew. The increasing number of newcomers to Fabriken meant that the regulars had to spend more time providing education in how to use the machines, at the expenses of their own experiments and projects. Moreover, the regulars' increased effort could not be properly rewarded: beyond full and free access to the space and social recognition, there was nothing more that could be offered them. In addition, it is difficult for newcomers to understand and accept how Fabriken and STPLN work. The idea of a commons, in which all concerned take care of the space, seems difficult to grasp because people often look for "someone 
in charge." The trickiest issue has to do with the sporadic users. Being in a space day after day helps a person to be aware of the importance of cleaning up and putting tools back where they belong. The regulars often have to spend time cleaning up messes made by others, and they often find that tools or materials seem to have disappeared. Moreover, because the space hosts a number of short-term projects, some participants may become very engaged for a while and then disappear from the space.

The problems emerging in the Fabriken and STPLN can be partially explained in terms of Elinor Ostrom's general design principles ${ }^{1}$ for sustainable commons (1990, 1999). Among regulars, sporadic users, and newcomers, there is an issue of fairness: newcomers and sporadic users get a proportionately bigger benefit for the effort they invest than the regulars. This suggests that there may be deficiencies in how the rules of use and access are communicated to newcomers. Moreover, Fabriken lacks a system for verifying and sanctioning misuse of the shared resources (Ostrom 1990, 1999)—a lack that raises the question of how to allow consistently for control over the common without investing too many resources when the number of participants gets too big for simple peer control.

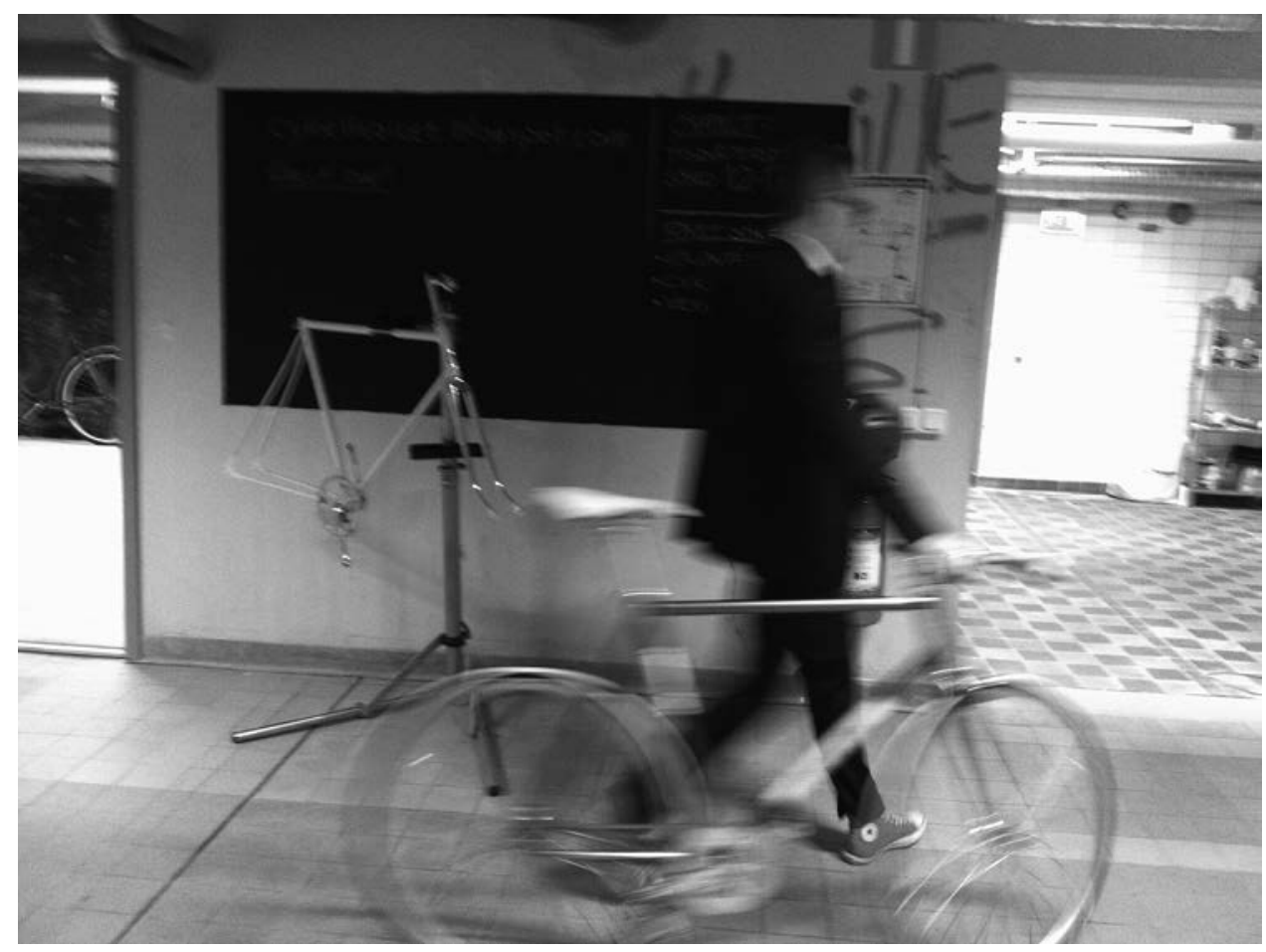

Figure 6.11

Transient participation. Anna Seravalli (CC:BY-NC). 
In Fabriken and STPLN there is clearly tension between embracing new participants, openness, and the intrinsic necessity for the commons to have defined boundaries (Ostrom 1990, 1999), specifically boundaries between legitimate participants and nonparticipants (Cox et al. 2010). However, it is important to note that Ostrom's principles are based on commons to which participants have a long-term commitment. As has already been pointed out, at STPLN participation is transient, which makes difficult to define a clear boundary between legitimate and non-legitimate participants. From this perspective, the role of the NGO as a partner appears to be fundamental in ensuring continuity to the commons, even though its way of operating could be improved (particularly in regard to informing newcomers and in regard to fairness).

A central challenge in spaces for opening production seems to be how to discourage free-riding and misuse by transient participants. It is also important to understand which approaches can be used to facilitate the inclusion of new participants in the commons, as doing so appears to be a fundamental step towards economies of scope.

\section{Sustainability, scope, and located production}

By attracting diverse practices, Fabriken and STPLN show how economies of scope can be at play in spaces for opening production. Economies of scope also figure in the financial sustainability of the entire premises. As has already been mentioned, most of the funding comes from the City of Malmö, which covers basic expenses such as electricity and heating. The municipality is also paying the salaries of the three people from the NGO. Other forms of financing come from the foundation subsidizing ReCreate and the Bicycle Kitchen and from the research center Medea, which invested in some of the machines and which pays the author's salary. Financial resources are also obtained by renting out the space for events or conferences. Some material resources are contributed by participants who share private machines and materials in the space.

However, sustainability is not just a matter of financial or material resources. Voluntary work-a great asset-is often repaid by social standing, but also in more tangible ways, such as the opportunity for the most engaged participants to hold parties and events in the space for no charge. From this perspective, STPLN is using economies of scope when it comes to rewarding participants' work.

The importance of participants' involvement in spaces for opening production is increasingly recognized-for example, a number of fab labs have implemented internal currency systems so that working hours can be exchanged for access to equipment or other privileges in a similar but more formal manner than is done in Fabriken. However, such a practice requires good calibration and continuous re-adaptation, as Fabriken's problem of participants' not being properly rewarded showed. The latter problem, in fact, led to a decision to hire someone to take care of the machines and of 
basic training, and to ask participants for a membership fee that could be paid either in money (which would be used to pay the technician's salary) or by working in the space.

In trying to work toward economies of scope, Fabriken and STPLN have made a major effort to focus on located production rather than local production. Instead of starting out from a defined set of machines and practices, STPLN has tried to adapt progressively to the practices emerging from and coming to the space and to see the space as supporting production practices that make sense in and work in the context of Malmö, rather than developing the space according to a more standardized format (for example, that of the fab lab).

\section{Infrastructuring for co-ownership and multiple understandings}

In setting up and running Fabriken and STPLN, a main concern has been how to develop meaningful relationships within the local context. The space has been built up starting from practices, rather than machines and technology. At the official opening, the premises were basically empty. Then, by engaging possible participants and hosting diverse initiatives, the premises were progressively equipped and developed.

In infrastructuring Fabriken, a number of diverse approaches have been taken. In the beginning, events were used to reach out to diverse audiences and to invite them to join the space. These events all had a similar loose format: people were invited to run their own activities. As time went by, we understood how these events worked well in attracting specific communities of makers, and that it was more difficult to create occasions to bring together diverse groups of participants. At the first Hackathon, ${ }^{2}$ in February 2011, we assumed that it was enough to include a few craft workshops to reach crafters. Some people interested in crafts did show up, but the majority of participants were still hackers. We also saw how, in reaching out to a wider public, more structured events (with planned activities and workshops) worked better than loose formats, as people less skilled in making seemed not so comfortable with an open format.

Other ways of involving people have been to organize courses and workshops. These public and planned activities have been very useful in involving people who already knew the space but had not yet found an opportunity to enter it.

Another important aspect in the infrastructuring of Fabriken has been working with a long-term perspective to establish co-ownership over the space, and to support the coexistence of diverse activities and interests.

Organizing events and workshops and setting up small-scale experiments have been important ways of inviting people to participate, but to get them to stay it has been important to provide them with ownership of the facilities and to involve them in the running of the space. It has also been important to find a way to keep many different initiatives with divergent interests under the same roof. Instead of trying to come to a univocal and shared definition of what the premises are about, the approach has been 


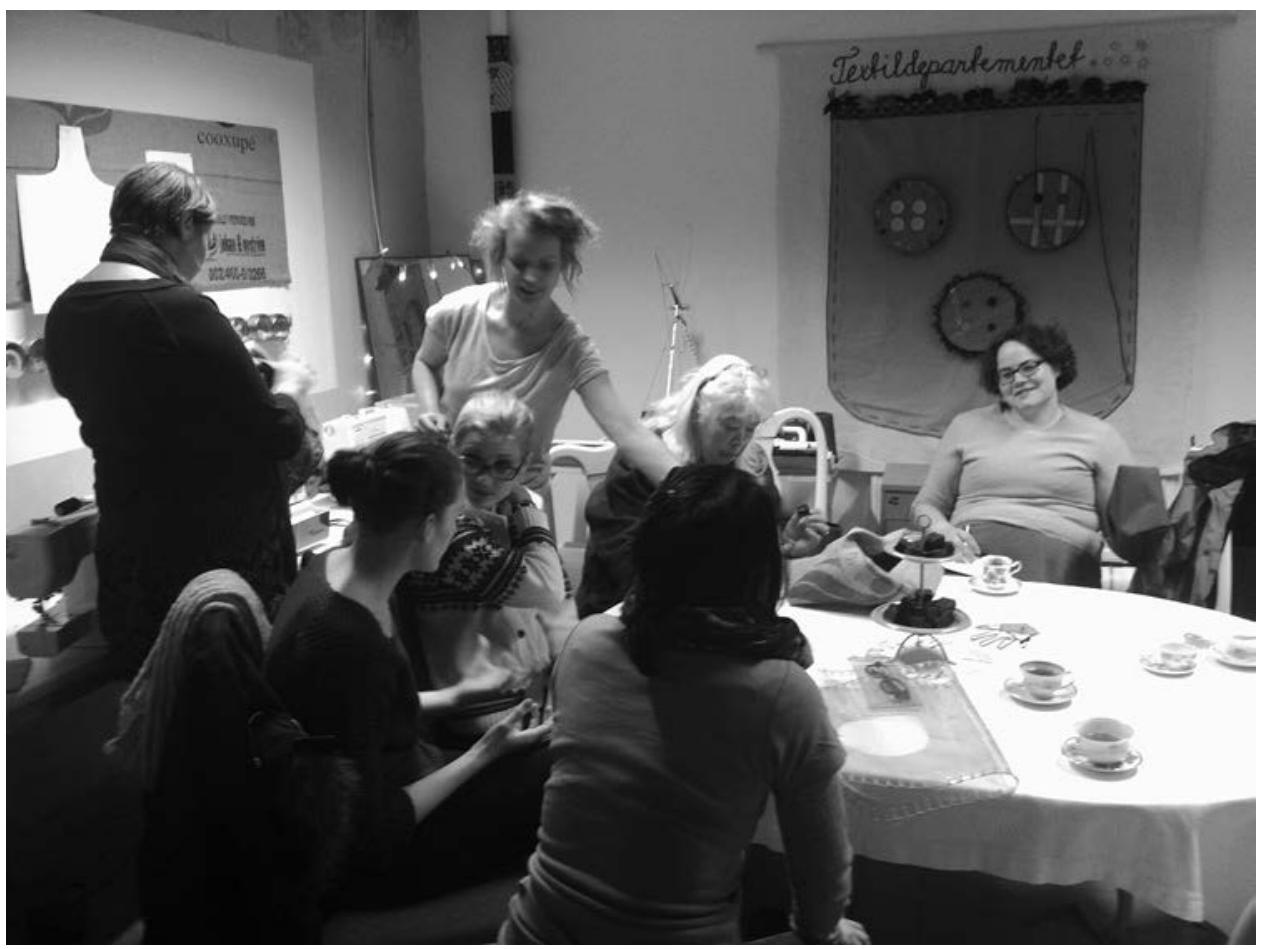

Figure 6.12

An afternoon workshop in the Textile Department. Anna Seravalli (CC:BY-NC).

to allow for diverse understandings of Fabriken and STPLN. We have encouraged participants to develop their own understandings of the space. This has been facilitated by the large size of the premises and by the opportunity to have diverse activities happening at the same time in diverse spaces, or in the same space at different times, so as to minimize the risk of friction. Allowing a multiplicity of understandings has been helpful in constructing co-ownership and working toward economies of scope; however, it may have played a negative role in matters of communication concerning rules and behavior.

\section{New producers and old producers: Alliances in the margins?}

The participants at Fabriken and STPLN, aside from their differences, can be described as "new producers": prosumers, amateurs, lead users, and, generally speaking, end users. There is a lack of more traditional producers such as artisans or small producers. Relationships with more traditional producers might help in gaining access to competences and to materials. 
Through ReCreate, when looking for material suppliers, a number of contacts with small producers were made. The collaboration with them rarely went beyond getting production leftovers, but when it did, interesting alliances seemed to emerge, as it happened with Bertil and his small die-board workshop that produces molds for punching cardboard and other materials. ReCreate founder, Carin, got in contact with him, as we wanted to experiment with the possibilities of creating building blocks out from various kinds of plastic and cardboard foils that ReCreate got from a packaging company. These initial contacts developed in an ongoing collaboration between Bertil and ReCreate, which entails not only punching foils, but also skills exchange.

Meeting and working with Bertil helped me to understand the situation of local small producers, revealing how promising but also how difficult it could be to involve them in a space for opening production.

In his collaboration with ReCreate, Bertil is working for free. When Carin, the founder of ReCreate, tried to discuss paying for his work and the die-boards, he just smiled and pointed out how expensive developing a die-board is. However, Bertil, who is in his seventies and ready to retire, seems to appreciate the fact that his skills and knowledge can be applied in new areas and, somehow, be passed on. Bertil not only has knowledge of traditional techniques of die-cutting; he is also an expert on lasercutting, which makes him, potentially, a great resource for Fabriken. Through Bertil it has also been possible to get in contact with a big supplier of plastic materials and looking for possibilities to get some materials from them. Moreover, working with Bertil has led to a better understanding of the situation of small producers around Malmö, which is quite discouraging. The die-board company has very few clients left, since, as Bertil once said, die-cutting, together with many other production activities, is now a Chinese business.

From this perspective, the third industrial revolution could also be about finding alliances that would enable new and old producers to exchange skills, knowledge, and material resources, but it could also be a way to support other practices defining new forms of local production. However, the collaboration with Bertil has been an exception. A number of attempts have been made to infrastructure with small producers in Fabriken, but none of them have succeeded. Once, for example, Fabriken hosted a workshop with a professional woodworker. When discussing the possibilities of collaborating with the space, he stated how the space could work well for teaching the basics of carving wood, but that he could never use it for his professional practice, since that would require the purchase of expensive machines that would be difficult to share because he would have to use them for long periods of time.

However, further exploration of how to infrastructure possible alliances between new and old producers may be worthwhile-collaborations between these two groups may turn out to be fruitful attempts at commoning production, as in the case of Carin and Bertil. 


\section{Conclusions}

The experiences emerging from Fabriken and STPLN can be considered as examples of what it might mean (and take) to infrastructure and to common for tangible production practices based on sharing and collaboration. The insights coming from the Malmö makerspace reveal the challenges posed by commons with transient participation, as well as how working toward economies of scope demands a located and ongoing approach in exploring possible alliances and practices.

Fabriken and STPLN seem to play a role also in relation to what kind of forms the third industrial revolution may take, at least, in Malmö. Inspired by the practices and activities emerging in this makerspace, the city of Malmö has commissioned us (the researchers) to do a pre-study for another similar facility in another neighborhood, where unemployment and integration are burning issues. The aim of this pre-study is to explore how a makerspace, by supporting the development of human capital and social capital, could improve well-being and living conditions in this area. Another interesting development is related to the national agency that financed our (the researchers) participation to Fabriken and STPLN. The financing of Fabriken and the other two Living Labs (see chapters 3 and 11) was part of an EU structural funds program aiming for economic growth. During the running of the Living Labs, a number of discussions and tensions have emerged in relation to the fact that the Labs were not delivering enough jobs and companies, which were two of the main indicators of the program. However, it is interesting to notice, one year after the official ending of the project, how the national agency has granted funding for the establishment of a number of makerspaces around the country (Tillväxtverket 2014).

In this perspective, it seems possible to say that a located and explorative engagement with practices, people, and spaces could be a way, at least on a local scale, to influence forms and aims of the third industrial revolution.

\section{Acknowledgments}

This chapter is a result of ongoing and located commons-based reflections with Pelle Ehn, Richard Topgaard, Luisa Carbonelli, Carin Hernqvist, Caroline Lundholm, Oyuki Matsumoto, Ola Persson, Bertil Björk, David Cuartielles, and the people who have been and are producing and commoning at STPLN.

\section{Notes}

1. These principles are not be understood as design approaches for the establishment of successful commons. They represent recurring characteristics that have been found in successful commons. (See Hess and Ostrom 2007.) 
2. The Hackathon is a format that emerged within hacker communities. Hackathons are 24-48hour events in which participants gather to program and build things together.

\section{References}

Anderson, Chris. 2010. In the Next Industrial Revolution, Atoms Are the New Bits (http://www .wired.com/magazine/2010/01/ff_newrevolution/).

Anderson, Chris. 2012. Makers: The New Industrial Revolution. Crown Business.

Baichtal, John. 2011. Hack This: 24 Incredible Hackerspace Projects from the DIY Movement. QUE.

Bauwens, Michel. 2006. The Political Economy of Peer Production. Post-Autistic Economics Review 37 (3): 33-44.

Bauwens, Michel. 2009. Class and Capital in Peer Production. Capital and Class 33: 121-141.

Benkler, Yochai. 2006. The Wealth of Networks. Yale University Press.

Benkler, Yochai. 2013. Commons and Growth: The Essential Role of Open Commons in Market Economies. University of Chicago Law Review 80: 1499-1555.

Björgvinsson, Erling, Pelle Ehn, and Per-Anders Hillgren. 2010. Participatory design and democratizing innovation. In Proceedings of the 11th Biennial Participatory Design Conference, Sydney.

Carson, Kevin. 2010. The Homebrew Industrial Revolution. Book Surge.

Cavalcanti, Guy. 2013. Is it a Hackerspace, Makerspace, TechShop, or FabLab? (http://makezine .com/2013/05/22/the-difference-between-hackerspaces-makerspaces-techshops-and-fablabs/)

Cox, Michael, Gwen Arnold, and Tomás Sergio Villamayor. 2010. A Review of Design Principles for Community-Based Natural Resource Management. Ecology and Society 15 (4): 38.

FabLab. 2013. FabLabs list (http://fab.cba.mit.edu/about/labs/).

Gauntlett, David. 2011. Making Is Connecting. Polity.

Gershenfeld, Neil A. 2005. Fab: The Coming Revolution on Your Desktop. Basic Books.

Greenhalgh, Paul, ed. 2002. The Persistence of Craft. Rutgers University Press.

Grenzfurthner, Johannes, and Frank Apunkt Schneider. 2009. Hacking the Space (http://www .monochrom.at/english/2009/05/hacking-spaces-critical-acclaim-of-what.htm).

Harvey, David. 2010. A Companion to Marx's Capital. Verso.

Helfrich, Silke. 2013. Economics and Commons?! Towards s Commons-creating Peer Economy. Keynote speech at conference on Economics and the Common(s): From Seed Form to Core Paradigm, Berlin.

Hess, Charlotte, and Elinor Ostrom, eds. 2007. Understanding Knowledge as a Commons: From Theory to Practice. MIT Press. 
Hess, Karl. 2005. Community Technology. Loompanics.

Leadbeater, Charles, and Paul Miller. 2004. The Pro-Am Revolution. Demos.

Linebaugh, Peter. 2009. The Magna Carta Manifesto. University of California Press.

Mota, Catarina. 2011. The Rise of Personal Fabrication. In Proceedings of the Eighth ACM Conference on Creativity and Cognition, Atlanta.

O'Mahony, S., and B. A. Bechky. 2008. Boundary Organizations: Enabling Collaboration among Unexpected Allies. Administrative Science Quarterly 53: 422-459.

Orsi, Cosma. 2009. Knowledge-Based Society, Peer Production and the Common Good. Capital and Class 33 (31): 31-51.

Ostrom, Elinor. 1990. Governing the Commons. Cambridge University Press.

Ostrom, Elinor, Dietz Thomas, Dolšak Nives, Stern C. Paul, Stonich Susan, and Weber U. Elke, eds. 2002. The Drama of the Commons. National Research Council.

Ostrom, Elinor. 1999. Design Principles and Threats to Sustainable Organizations That Manage Commons. Workshop in Political Theory and Policy Analysis, and the Center for the Study of Institutions, Population and Environmental Change, Indiana University.

Ostrom, Elinor. 2011. Background on the Institutional Analysis and Development Framework. Policy Studies Journal 39 (1): 7-27.

P2P Foundation. 2013. Peer Production (http://p2pfoundation.net/Peer_Production\#Discussion_2: _Is_Peer_Production_Beyond_Capitalism.3F).

Panzar, C. John, and D. Robert Willig. 1981. The Economies of Scope. American Economic Review 71 (2): 268-272.

Putnam, Robert. 1995. Bowling Alone: America's Declining Social Capital. Journal of Democracy 6 (1): $65-78$.

Rifkin, Jeremy. 2011. The Third Industrial Revolution: How Lateral Power Is Transforming Energy, the Economy, and the World. Palgrave Macmillan.

Ruskin, John. 1985. Unto This Last and Other Writings. Penguin.

Sennett, Richard. 2008. The Craftsman. Yale University Press.

Seravalli, Anna. 2013. Prototyping for Opening Production: From Designing for to Designing in the Making Together. Presented at European Academy of Design Conference on Crafting the Future, Gothenburg.

Shove, Elizabeth, Matthew Watson, and Martin Hand. 2007. The Design of Everyday Life. Berg.

Siefkes, Christian. 2012. Beyond Digital Plenty: Building Blocks for Physical Peer Production. Journal of Peer Production (http://peerproduction.net/issues/issue-1/invited-comments/beyond-digital -plenty/). 
Star, Susan Leigh, and Karin Ruhleder. 1995. Steps toward an Ecology of Infrastructure: Design and Access for Large Information Spaces. Information Systems Research 7: 111-134.

Thrift, Nigel. 2006. Re-Inventing Invention: New Tendencies in Capitalist Commodification. Economy and Society 35 (2): 279-306.

Tillväxtverket. 2014. Pressmeddelande (http://www.tillvaxtverket.se/download/18.48a604441429 f3886202ca2/1387447430244/Bilaga+pressmeddelande_om+projekten.pdf).

Troxler, Peter. 2010. Commons-based Peer-Production of Physical Goods Is there Room for a Hybrid Innovation Ecology? Presented at Free Culture Research Conference, Berlin.

Troxler, Peter. 2013. Making the 3rd Industrial Revolution. The Struggle for Polycentric Structures and a New Peer-Production Commons in the Fab Lab Community. In FabLabs: Of Machines, Makers and Inventors, ed. J. Walter-Herrmann and C. Büching. Transcript.

van Abel, Bas, Luca Evers, Roel Klaassen, and Peter Troxler. 2011. Open Design Now. BIS.

von Busch, Otto. 2008. Fashion(able): Hacktivism and engaged fashion design. Art Monitor.

von Hippel, Erik. 2005. Democratizing Innovation. MIT Press.

Wikipedia. 2011. Hackerspace (http://en.wikipedia.org/wiki/Hackerspace).

Zijlstra, Ton. 2013. The Failings of FabLabs (http://fablab.nl/2013/09/29/the-failings-of-fablabs/). 
